\section{Nuclear Magnetic Resonance Evidence for the Diborohydride Ion in Polyethylene Glycol Ethers}

THE complex formed by absorption of diborane in solutions of borohydride ion in polyethylene glycol ethers is of considerable interest because it probably contains the simplest $\mathrm{B}-\mathrm{H}-\mathrm{B}$ bridge system known. Brown et al. ${ }^{1}$ reported that solutions of sodium or lithium borohydride in diethylene glycol dimethyl ether absorb a half molar equivalent of diborane. On this evidence it was suggested that the diborohydride ion $\mathrm{B}_{2} \mathrm{H}^{-}$was present and that its structure probably contained a single $\mathrm{B}-\mathrm{H}-\mathrm{B}$ bridge.

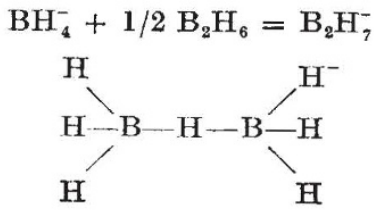

Baker et $a l .^{2}$ report a similar reaction on electrolysis of a solution of sodium borohydride in diethylene glycol dimethyl ether :

$$
\begin{aligned}
& \mathrm{BH}_{4}^{-}-e=\mathrm{BH}_{3}+1 / 2 \mathrm{H}_{2} \\
& \mathrm{BH}_{3}+\mathrm{BH}_{4}^{-}=\mathrm{B}_{2} \mathrm{H}_{7}^{-} \\
& \mathrm{B}_{2} \mathrm{H}_{7}^{-}-e=\mathrm{B}_{2} \mathrm{H}_{6}+1 / 2 \mathrm{H}_{2}
\end{aligned}
$$

Several attempts ${ }^{1,2}$ have been made to prepare the salt in a pure form but so far it has not been possible to prepare a salt with less than one molecule of solvent per molecule of the salt ${ }^{2}$.

This work describes an attempt to confirm the structure using $\mathrm{B}^{11}$ and $\mathrm{H}^{1}$ nuclear magnetic resonance. Independently, the $\mathrm{B}^{11}$ nuclear magnetic resonance spectrum has been studied by Gaines ${ }^{3}$.

The $\mathrm{B}^{11}$ nuclear magnetic resonance spectra were obtained using a Varian $4200 B$ wide-line spectrometer at a frequency of $10.9 \mathrm{Mc} / \mathrm{s}$ on a dispersion mode with $20 \mathrm{c} / \mathrm{s}$ field modulation. The spectra obtained are similar to those found by Gaines ${ }^{3}$. Solutions of sodium borohydride were made up direct and placed in a vacuum line. After the line was evacuated, diborane was allowed to stand over the solution for several hours. The $\mathrm{B}^{11}$ nuclear magnetic resonance spectrum showed the complete disappearance of the borohydride quintet and the appearance at lower field of a $1: 3: 3: 1$ quartet with $J=110 \pm 5 \mathrm{c} / \mathrm{s}$. This splitting is slightly greater than that reported by Gaines ${ }^{3}$. Solutions obtained by electrolysis in an apparatus similar to that described by Baker et al..$^{2}$ showed a spectrum identical to that of the solutions obtained by absorption. This therefore confirms that the same species is present in both solutions.

The $1: 3: 3: 1$ quartet is due to splitting of the $\mathrm{B}^{11}$ resonance line by three equivalent protons. The bridge proton would be expected to split each component of the quartet into a doublet. This splitting was not observed in this work or by Gaines. The lines are, however, somewhat broadened. The value of $J$ is similar to that observed for other boranes and also for $\mathrm{BH}_{3}$ bonded to an ether solvent4. Chemical evidence, however, suggests that the $\mathrm{BH}_{3}$ group would not combine with the solvent at room temperature. Diborane is only slightly soluble in diethylene glycol dimethyl ether ${ }^{5}$ and does not therefore dissociate to any appreciable extent. Such an explanation of the $\mathrm{B}^{11}$ nuclear magnetic resonance spectrum does not account for the stoichiometry of the absorption reaction and gives no indication of the position of the negative charge.

$\mathrm{H}^{1}$ nuclear magnetic resonance spectra were examined at $30 \mathrm{Mc} / \mathrm{s}$ on a high-resolution spectrometer built by Richards ${ }^{6}$. The spectrum of sodium borohydride in diethylene glycol dimethyl ether was obtained with some difficulty due to the high noise-level at the sensitivity required. On absorption of diborane into such solutions the borohydride ion lines disappeared but were not replaced by any new lines. This suggests that the $\mathrm{H}^{1}$ resonance lines of the diborohydride ion are broadened and thus not observed because of the high noise-level. This broadening and the absence of further splitting in the $\mathrm{B}^{11}$ nuclear magnetic resonance spectrum could be due to exchange of the bridge proton. Lipscomb ${ }^{7}$ suggests the bridge may be unsymmetrical with exchange between two equivalent proton positions. Further investigations of the $\mathrm{H}^{1}$ nuclear magnetic resonance spectrum with a suitably sensitive high-resolution spectrometer might be very interesting and might elucidate the structure completely.

Although not confirming absolutely, it seems more likely from this work and that of Gaines that the diborohydride ion does contain a single $\mathbf{B}-\mathbf{H}-\mathbf{B}$ bridge. The diborane used in this work was prepared by the action of potassium borohydride on phosphoric acid as described by Duke et al. ${ }^{8}$ One of us (B. J.D.) thanks the Gas Council for the award of a scholarship.

\section{B. J. DUKE*}

Inorganic Chemistry Laboratory,

O. W. Howarth

J. G. Kenworthy

Physical Chemistry Laboratory, University of Oxford.

*Present address, Department of Chemistry, University of Reading.

' Brown, H. C., Tierney, P. A., and Stehle, P. F., J. Amer. Chem. Soc., 79 2020 (1957).

s Baker, E. B., Ellis, R. B., and Wilcox, W. S., J. Inorg. Nucl. Chem., 23, 41 (1961).

${ }^{3}$ Gaines, D. F., Inorg. Chem., 2, 523 (1963).

- Phillips, W. D., Miller, H. C., and Muellerton, L. L., J. Amer. Chem. Soc., 81, 4496 (1959).

${ }^{5}$ Mullen, J. W., Dist. Abs., 21, 3390 (1961).

- Richards, R. E., Leane, J., and Schaeffer, E., J. Sci. Instr., 36, 230(1959).

"Lipscomb, W. N., Boron Hydrides, 21 (W. A. Benjamin Inc., New York, 1963)

s Duke, B. J., Gilbert, J. R., and Read, I. A., J. Chem. Soc., 540 (1964).

\section{Effect of Temperature on the Photosensitized Degradation of Textile Fibres}

The importance of oxygen and water vapour on the photosensitized degradation of textile fibres by near ultraviolet and visible light has been demonstrated ${ }^{\mathbf{1}}$; but the effect of temperature on these reactions has received little attention. Because of the fluctuating intensity of sunlight and consequently the difficulty of accurate temperature control, we have used in our experiments an artificial light source (400-W high-pressure mercury-vapour lamp), which has been shown ${ }^{1}$ to produce qualitative results similar to those of sunlight. The textile fibres were exposed in the form of yarns in the interior portion of a double-walled glass cell (diam., 1.5 in. int., $2 \cdot 0$ in. ext.). The temperature of the cell was controlled by passing water or steam continuously through the annular space. Dry air pre-warmed to the requisite temperature was passed continuously through the central portion of the cell at 0 per cent relative humidity, and a quantity of water not in contact with the fibre was maintained at the bottom of the cell at 100 per cent relative humidity. For the short exposure periods involved in these experiments the thermal degradation occurring in the dark was negligible.

Titanium dioxide is widely used as a delustrant for man-made textile fibres, the pigment being usually incorporated in the polymer mass prior to extrusion. Although the pigment must be present in the fibre in much larger aggregates than is the case with vat dyes applied to textile fibres by conventional dyeing processes, nevertheless there are considerable similarities in the behaviour of these two types of sensitizer in the photo- 